\title{
Assistência odontológica no país: perspectivas 2
}

\author{
Hélio Uchôa ${ }^{*} \quad$ "Escola Nacional de Saúde \\ Pública - FIOCRUZ - RJ
}

A questão da assistência odontológica no Brasil, operando uma vasta e complexa rede de consultórios vinculados aos Setores Público ou Privado, deve ser analisada sob este duplo aspecto.

$O$ funcionamento dessa rede envolve características pertinentes aos dois setores, relacionadas com a situação econômica dos pacientes, os tipos de procedimentos prestados, as relaçðes de trabalho, cuja prática vem sendo feita através da utilização de modelos gerenciais coerentes com as formas de sistemas capitalistas, voltadas para a proteção da força de trabalho e do controle social. ${ }^{3}$

$\mathrm{Na}$ dimensão econômica, a odontologia em nosso país ainda se caracteriza como uma profissão essencialmente liberal, conforme comprovam os estudos realizados por Pinto, 5 quando demonstrou que o setor privado participou com $82 \%$ da composição dos gastos totais da população com cuidados odontológicos, no ano de 1981, enquanto que o setor público com apenas $18 \%$.

Embora os procedimentos clínicos prestados através da rede particular sejam, na sua grande maioria, reconhecidamente de elevado padrão técnico-científico, a nível dos países mais desenvolvidos, esses benefícios vêm privilegiando reduzida parcela da população, estimada em menos de $5 \%$. Por outro lado, as familias de baixa renda somente teriam condições econômicas para remunerar serviços odontológicos mais simples e gerais prestados pelas chamadas "clínicas populares". Ficando mais de 60 milhőes de pacientes à conta, exclusiva, do setor público, cujo desempenho vem sendo questionado em face da sua reconhecida ineficiência e ineficácia, na medida em que não satisfaz a expectativa dos pacientes, dos profissionais e da comunidade como um todo.

A crise da assistência odontológica não ocorre de maneira isolada, ela está ligada à própria crise social, econômica e política que acomete o país, consubstanciada pela distorção do sistema formador de recursos humanos. Mesmo considerando-se que "o ensino da odontologia vem, nestes últimos anos, sofrendo profundas modificações", ${ }^{4}$ constata-se, ain$\mathrm{da}$, que o sistema continua preparando profissionais voltados para atuar na iniciativa privada, “... para resolverem os problemas do paciente como individuo, sem contudo levar 
em consideração os fatores que condicionavam e condicionam a situação do paciente, dos seus dependentes e da comunidade", 4 não obstante parcela representativa desses profissionais atuar em serviços odontológicos de saúde pública.

A discreta eficácia do sistema odontológico pode ser medida a partir de dados de levantamentos epidemiológicos da cárie dental, com a utilização do índice CPOD (média de dentes cariados, perdidos e obturados), que, além de mensurar a prevalência, registra a evolução da cárie durante toda a vida, destacando, tam bém, o grau da atenção prestada em seus aspectos quantitativos e qualitativos, de acordo com a história do tratamen to das necessidades.

A análise das Tabelas I e II e do Gráfico 1, contendo dados de levantamentos do indice CPOD realizados em escolares a partir dos seis anos de idade, época em que os dentes permanentes iniciam sua erupção, conjugados com dados de estudos realizados em adultos, permite concluir que:

a) a prevalência da cárie dental é reconhecidamente elevada em todos os grupos etários, principalmente de seis a 10 anos, ao apresentar, em média, quatro dentes CPO por criança e o maior incremento (28\%) (Tabela I);

b) o ataque da cárie dental dos seis aos 25 anos de idade corresponde, em média, a um dente por ano, baixando em torno de 0,2 nas idades subseqüentes até aos 45 anos (Tabela I);

c) as necessidades de restaurações apresentam seu ponto máximo no grupo de seis a 10 anos, com $85 \%$, baixando acentuadamente nos demais grupos etários, em conseqüência da redução do percentual de dentes cariados e aumento dos dentes perdidos (Tabela II e Gráfico 1), observando-se, claramente, uma inversão dos componentes " $C$ " e "P";

d) na composição do índice CPO, o elemento "P" (dentes perdidos) evolui rapidamente de $19 \%$, no grupo e tário de 11 a 15 , para $55 \%$, no grupo dos 21 aos 25 anos (Gráfico 1);

e) que o procedimento "nobre" da atenção odontológi$\mathrm{ca}$, dente restaurado (componente " $O$ "), se mantém extremamente baixo em todos os grupos etários (Gráfico 1).

Estas conclusões mostram, em última análise, que a prática odontológica e a prestação de serviços oferecidos à população de baixa renda, escolares e pacientes do setor público, estão vol tadas quase exclusivamente para o atendimento das exodontias da clientela que, espontaneamente, procura 
resolver seus problemas emergenciais nos Centros de Saúde das Secretarias Estaduais e Municipais de Saúde, Postos de Assistência Médica do INAMPS, clínicas de empresas estatais e paraestatais etc., constituída, principalmente, de grupos etários acima dos 15 anos, quando a cárie dental, abandonada ao seu próprio curso, evolui às etapas terminais da doença, onde a eliminação do elemento é o tratamento indicado. Com o aumento das exodontias, surge um outro tipo de necessidade, "as pontes fixas", instalando-se muito cedo na vida do adolescente e, posteriormente, as "dentaduras" começam precocemente a serem indicadas, aumentando continuamente durante toda a vida.

\section{TABELA I}

Média do CPOD em ambos os sexos, de seis a 55 anos de idade, distribuidos por grupos etários

\begin{tabular}{lrrrrrc}
\hline $\begin{array}{l}\text { Grupos } \\
\text { Etários }\end{array}$ & Cariados & Perdidos & Obturados & $\begin{array}{r}\text { Total } \\
\text { CPOD }\end{array}$ & $\begin{array}{c}\% \\
\text { Incremento }\end{array}$ \\
\hline 06 & 10 & 3,43 & 0,50 & 0,10 & 4,03 & 28 \\
11 & 15 & 7,13 & 1,88 & 0,92 & 9,93 & 35 \\
16 & 20 & 7,63 & 5,62 & 0,45 & 13,72 & 42 \\
21 & 25 & 8,16 & 10,33 & 0,35 & 18,75 & 58 \\
26 & 30 & 6,59 & 11,07 & 0,36 & 19,04 & 59 \\
31 & 35 & 6,70 & 13,97 & 0,47 & 21,15 & 66 \\
36 & 40 & 5,50 & 16,13 & 0,36 & 22,01 & 68 \\
41 & 45 & 4,86 & 18,93 & 0,28 & 24,19 & 75 \\
46 & 50 & 4,72 & 19,27 & 0,30 & 24,29 & 76 \\
51 & 55 & 4,63 & 19,44 & 0,31 & 24,48 & 77 \\
\hline
\end{tabular}

Fonte: Levantamento realizado pela FSESP, grupo de seis a 14 anos Levantamento realizado pela ENSP, grupo de 15 a 55 anos

\section{TABELA II}

Composição percentual do indice CPOD, em ambos os sexos, idade de seis a 55 anos, por grupos etários

\begin{tabular}{lccccc}
\hline \multirow{2}{*}{$\begin{array}{l}\text { Grupos } \\
\text { Etários }\end{array}$} & \multicolumn{5}{c}{ Percentual } \\
\cline { 2 - 6 } \multicolumn{1}{l}{ Cariados } & Perdidos & Obturados & CPOD \\
\hline 06 & 10 & 85 & 13 & 02 & 100 \\
11 & 15 & 72 & 19 & 09 & 100 \\
16 & 20 & 56 & 41 & 03 & 100 \\
21 & 25 & 43 & 55 & 02 & 100 \\
26 & 30 & 35 & 63 & 02 & 100 \\
31 & 35 & 32 & 66 & 02 & 100 \\
36 & 40 & 25 & 73 & 02 & 100 \\
41 & 45 & 20 & 79 & 01 & 100 \\
46 & 50 & 19 & 79 & 01 & 100 \\
51 & 55 & 19 & 80 & 01 & 100 \\
\hline
\end{tabular}

Fonte: Levantamento realizado pela FSESP, grupo de seis a 14 anos Levantamento realizado pela ENSP, grupo de 15 a 55 anos

Cadernos de Saúde Pública, R.J., 1 (2), abr/jun, 1985. 


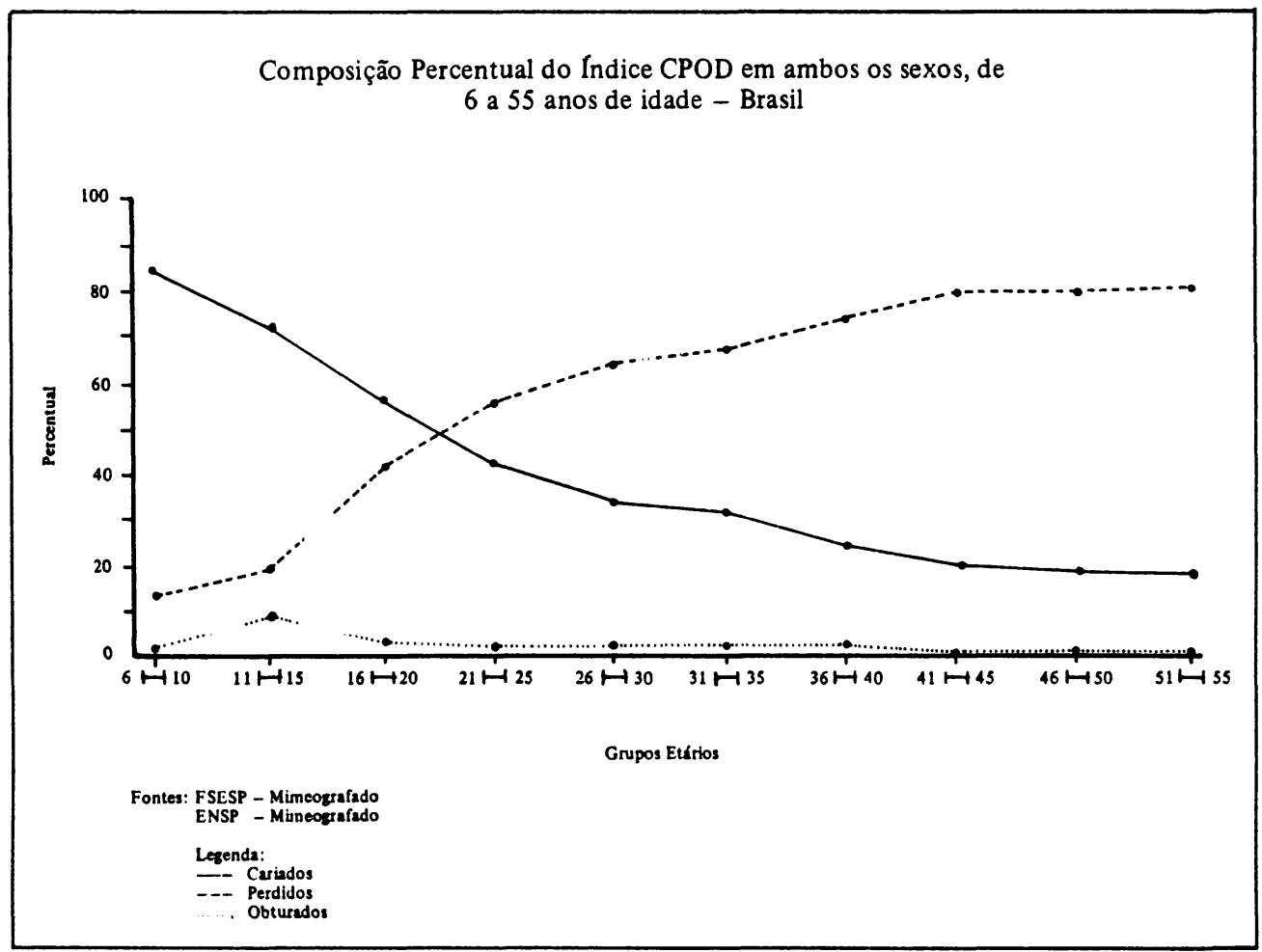

A organização dos serviços odontológicos do setor público, independente da considerável parcela da população brasileira e do elevado volume de necessidades de tratamento, por um lado, e da limitação dos recursos financeiros, por outro, deve priorizar a democratização da assistência odontológica, através de uma estrutura piramidal de serviços.

$\mathrm{Na}$ base da pirâmide se localizariam, prioritariamente, os programas vol tados para o atendimento do grupo mais vulnerável epidemiologicamente, as crianças de seis a 12 anos. Os procedimentos mais simples e gerais seriam prestados pelas clínicas dos Centros de Saúde das Secretarias Estaduais e Municipais de Saúde, Postos de Assistência Médica do INAMPS etc., com o propósito de atender à demanda espontânea. As açðes mais complexas e sofisticadas seriam concentradas nas Unidades Hospitalares, onde já se desenvolvem atividades de cirurgia e traumatologia buco-maxilofacial e cuidados de emergência.

$O$ atendimen to do grupo de seis a 14 anos, enfatizando a implementação de medidas preventivas em massa, desenvolvimento de atividades educativas e tratamento da cárie den. tal, seria desenvolvido através da implantação do "Sistema Incremental", 1, 2,6 que se caracteriza pela sua ação difásica, através do atendimento preventivo e curativo, sendo 
cada fase orientada no sentido da redução de uma das dimensões do problema. A fase preventiva reduz a incidência de cárie dental e a fase curativa atua de forma a evitar a complexidade do tratamento, com o propósito de eliminar as necessidades acumuladas, somente possível mediante 0 acompanhamento da criança dos seis aos 14 anos (período em que se processa a erupção dos dentes permanentes). Para viabilizar este acompanhamento ao longo de nove anos, torna-se necessário dirigir o atendimento para uma população "cativa" - o escolar - nas dependências da própria escola. Por outro lado, este procedimento apresenta ou tras vantagens, como por exemplo: facilidade de acesso da clientela, efeito psicológico nas próprias crianças e a relação positiva que se estabelece entre a equipe odontológica, o corpo docente, os escolares e os pais.

Esta proposta se fundamenta no princípio da simplificação, a saber:

- simplificação do equipamento;

- simplificação e padronização do instrumental e materiais;

- simplificação e padronização das técnicas e proce. dimentos, através da diminuição de passos;

- racionalização do espaço físico, para melhor desempenho do trabalho em equipe;

- transferência de conhecimento tecnológico e científico;

- utilização correta de pessoal auxiliar.

A organização de programas odontológicos voltados para o atendimento escolar, com base no "Sistema Incremental" tem apresentado resultados altamente satisfatórios, na medida em que procura elevar ao máximo a cobertura da população alvo, reduzindo ao mínimo as necessidades individuais. Para atingir este objetivo, é indispensável atuar na incidência das necessidades e do grau de atenção. $\mathrm{O}$ atendimento poderá ser dimensionado a partir da proposta de programas do tipo:

\section{MODELO INTENSIVO}

Este modelo consiste em proporcionar o tratamen to preventivo e curativo de todas as crianças de sete a 14 anos de idade no primeiro ano de trabalho e, nos subseqüentes, prestar tratamento inicial às novas crianças matriculadas e, simultaneamente, realizar o tratamento de manutenção a todo o grupo atendido anteriormente.

\section{MODELO GRADUAL}

Este modelo alternativo pode ser indicado quando os recursos são limitados. Neste caso, o atendimento no primeiro 
ano é restrito às crianças de menor idade (sete e oito anos), podendo avançar por outros grupos etários, dependendo do número de crianças em cada idade e o volume das necessidades de tratamento, da produtividade dos dentistas, do pessoal auxiliar disponivel (em quantidade e qualidade).

No ano seguinte, serão atendidas as novas crianças de sete a oito anos, e dar-se-á tratamento de manutenção às crianças atendidas no ano anterior. Este esquema é repetido nos anos seguintes, até que se tenha sob controle todas as crianças de sete a 14 anos de idade matriculadas na escola.

No processo de programação das atividades assistenciais odontológicas, deve-se primeiramente conhecer as necessidades de tratamento do grupo, mensuradas através de levantamentos epidemiológicos, complementadas pelo conhecimento das condições sócio-econômicas da clientela, bem como da produ tividade da equipe.

Não obstante se aceitar que a proposta do atendimento da cárie dental com base no "Sistema Incremental" não é recente, já que a Fundação Serviços de Saúde Pública (FSESP), pioneira no campo da Odontologia Social no Brasil, utiliza e desenvolve este sistema assistencial desde 1953, ultimamente vem se observando a implantação de alguns projetos de impacto, destacando-se o Projeto Integrado de Saúde Escolar - PISE - em Brasília, e o de Odontologia Simplificada da Pontifícia Universidade Católica de Belo Horizonte, que têm sido amplamente difundidos pelo país, e, como conseqüência, constata-se a existência de projetos idênticos implantados ou em fase de implantação, em vários .Estados.

$\mathrm{Na}$ realidade, estamos vivendo um momento histórico da Odontologia Social, na medida em que se observam significativas mudanças não só tecnológicas mas, sobretudo, dos profissionais de saúde em relação ao problema.

\section{REFERENCIAS BIBLIOGRÁFICAS}

1. CHAVES, M.M. Odontologia social. Rio de Janeiro, Labor do Brasil, $1977.450 \mathrm{p}$.

2. GONÇALVES, J.B. Projeto de Odontologia PRODENT. Goiânia, Fundação Ação Social do Palácio, 1981, mimeo.

3. MENDES, E.V. Producción de conocimientos para la práctica odontológica en América Latina. In: Conferencia Udual Facultades de Odontología de América Latina, 1. São Domingos, 1980.

4. MENDONÇA, A.R. Experiência do ensino na clinica integrada; 8? semestre; Rio de Janeiro, UFRJ, 1972. 
5. PINTO, V.G. Seminário sobre odontologia social; depoimento. RGO, 31 (1) jan./mar., 1983.

6. RIO DE JANEIRO (Estado) Secretaria Estadual de Saúde e Higiene. Programa de reorientação da odontologia. Rio de Janeiro, 1985. mimeo. 